\section{Variation of blood pressure during topical phacoemulsification}

\begin{abstract}
Background The changes of blood pressure in patients undergoing cataract procedure are not well studied. The blood pressures of cataract patients often become uncontrolled intraoperatively causing the procedure to be postponed. Intraoperative rise in blood pressure has been associated with ocular complications such as suprachoroidal haemorrhage and can be fatal from stroke or even myocardial infarction. We attempt to study the changes in blood pressure of patients undergoing cataract surgery. Aim Prospective study on the variation of blood pressure pre- and intra-operatively. Method The blood pressure readings of patients going for cataract procedures were measured in five stages during the pre-assessment clinic, on arrival at the day surgery, at the anaesthetic room, on the operating table intraoperatively; and postoperatively. The readings were compared to their age, sex, past medical history, and use of antihypertensive medication.
\end{abstract}

Department of
Ophthalmology, Watford General Hospital, Watford, UK

Correspondence: YC Yap, Department of Ophthalmology, Watford General Hospital, Vicarage Road, Watford WD18 OHB, UK

Tel: +44 1923 217513/

+44 7984232934 .

E-mail: eyapyc@

gmail.com

Received: 9 July 2007 Accepted in revised form: 16 September 2007

Published online:

19 October 2007
Results The rise in systolic blood pressures between intraoperative readings and those at the preassessment and anaesthetic room was highly statistically significant.

Being older ( $>65$ years of age), taking more than two antihypertensive drugs, being hypertensive, or having a family history of hypertension does not appear to increase the risk.

Conclusion Our study showed that there is a significant rise in systolic blood pressures especially in females during topical phacoemulsification. Further studies are needed on the factors that determine this increase and the changes in blood pressures during different stages of the procedure. Eye (2009) 23, 416-420; doi:10.1038/sj.eye.6703006; published online 19 October 2007
YC Yap, WW Woo, T Kathirgamanathan, A Kosmin, B Faye and S Kodati

Background

Phacoemulsification under topical anaesthesia has advantages over local or general anaesthesia. These include avoidance of complications related to general anaesthesia, reduced theatre time for patients, and efficient usage of the operating room. However, the rise in blood pressures during phacoemulsification has been questioned by the surgeon and the anaesthetist who would like the procedure to be safer. Possible causes of increased blood pressure can include discomfort and pain from the microscope light, iris manipulation, phacoemulsification, irrigation, aspiration, and intraocular lens implantation. ${ }^{1}$ Apart from life-threatening events such as myocardial infarctions or strokes, uncontrolled blood pressures can lead to suprachoroidal haemorrhage $^{2}$ and even retinal vascular occlusion intraoperatively.

Variation of blood pressures may depend on the patient's state of health, age, surgical techniques, and the surgeon's skills. In one study, Suzuki et $a l^{3}$ reported an increase in the preoperative blood pressure and a decrease in the postoperative levels. In another study on 39 patients, 19 of them showed a $20 \%$ or greater increase in systolic arterial pressure measured intraoperatively. ${ }^{4}$ Our study investigated the effect of phacoemulsification under topical anaesthesia on the blood pressures.

\section{Method}

Fifty-five patients listed for elective cataract surgery during the period from February 2007 to May 2007 were recruited for the study. They were first seen during preassessment 2 weeks before their cataract surgery. Their blood pressures were checked together with questions asked regarding their general health and medications taken. 
Informed consents were taken from the patients on participation for the blood pressures study.

Patients requiring general anaesthetic or regional blocks such as peri-bulbar or subtenons were excluded from the study. Patients found to have excessively high blood pressures on the day of operation and those needing antihypertensive intervention intraoperatively were also excluded from the study.

Five blood pressure readings were taken from the patient in total: (1) in the preassessment clinic 2 weeks before, (2) on arrival on the day of surgery, before installation of dilating drops, (3) in the anaesthetic room before surgery, (4) intraoperatively, and (5) postoperatively $30 \mathrm{~min}$ after transfer to the recovery ward.

The blood pressures were measured at the upper extremity with a blood pressure cuff at a height equal to the level of the patient's heart. They were taken after the patients have been in a sitting position for $5 \mathrm{~min}$ with automated blood pressure instruments. All blood pressure readings were taken with the patients sitting up except when the patients were in the anaesthetic room and intraoperatively, when they were supine.

Dilating medications used include $2.5 \%$ phenylephrine, $1 \%$ tropicamide, and Ocufen. Topical anaesthetics used include $1 \mathrm{ml}$ of $0.5 \%$ proxymethocaine $5 \mathrm{~min}$ before the procedure. If the patient complained of pain, appeared anxious, or squeezed on the lid speculum, an additional $0.3-0.5 \mathrm{ml}$ of $0.5 \%$ proxymetacaine was given. The patients were not given premedication orally or intravenously.

Phacoemulsifications were performed by two consultants in the unit. Intraoperatively, the blood pressures were measured every $5 \mathrm{~min}$ and the highest readings were recorded. A portion of $0.5 \mathrm{mg}$ of 1 in 1000 adrenaline was added to $500 \mathrm{ml}$ of balance salt solution for further dilation of the pupil during

phacoemulsification.

Oxygen supply at $21 \mathrm{~min}^{-1}$ was provided to the patient under the drape. Intracameral vancomycin was given postoperatively and the wounds were hydrosealed with no suture used.

Postoperatively, the patients were rested at the waiting area for at least $30 \mathrm{~min}$ before their blood pressure readings were taken.

Results were analysed using Window Excel 2007 and SPSS 15.0 (SPSS Inc., Chicago, IL, USA) to ensure data quality.

\section{Results}

Of the 55 patients, 7 were excluded from the study, as we could not complete all five readings. Fourty-six (83.6\%) patients completed the study protocol and could be included in the blood pressure analysis. Six (13.0\%) patients were below 65 years while $40(87.0 \%)$ were above the age of 65 (median $=80$ years, range $41-91$ years). There were 19 males $(41.3 \%)$ and 27 females $(58.7 \%)$. Twenty-seven $(58.7 \%)$ of the patients were hypertensive while six $(13.0 \%)$ had a family history of hypertension.

Comparing the paired $t$-test results on the different settings, the rise of systolic blood pressures measured intraoperatively and at the preassessment and anaesthetic room was highly statistically significant. The increase in diastolic blood pressures between preassessment and intraoperatively was statistically significant. There was a $14.78 \%$ rise in systolic blood pressures and an increase of $7.43 \%$ in diastolic blood pressures between the intraoperative and preassessment readings.

On comparison between the gender, females had a higher risk of rise in systolic blood pressures and this was moderate and statistically significant $(P=0.07)$.

No significant change was found in both the systolic and diastolic blood pressures between the two groups of patients. Being older ( $>65$ years of age), taking more than two antihypertensive medicines, or having a family history of hypertension does not appear to increase the risk.

\section{Discussion}

The increase in blood pressure intraoperatively was thought to be a response to pain. Fichman asked 600 of his cataract patients who underwent topical anaesthesia to rate their level of discomfort during surgery. Eighty per cent of them reported having mild discomfort, $8 \%$ moderate, and $3 \%$ severe pain. He also monitored the blood pressure of 100 patients and only $1 \%$ of them had raised blood pressure. ${ }^{5}$

There is an increased risk of 2.13 times of having cataract extraction in hypertensive patients, especially those between 60 and 69 years of age compared with non-hypertensives as reported in one study. ${ }^{6}$ However, being hypertensive does not seem to be a risk for rise in blood pressure in this study.

The concentration of phenylephrine used for our cataract patients was $2.5 \%$. Kenawy et $a l^{7}$ reported some increase of both systolic and diastolic blood pressures in patients who had phenylephrine with concentration of $10 \%$ instilled compared to $2.5 \%$ but the increase was not statistically significant. Malhotra et $a l^{8}$ and Symons et $a l^{9}$ reported no change in the blood pressures between the two different concentrations of phenylephrine.

Limitations of the study include the small number of patients recruited with blood pressure measurements taken by five different ambulatory machines in different 


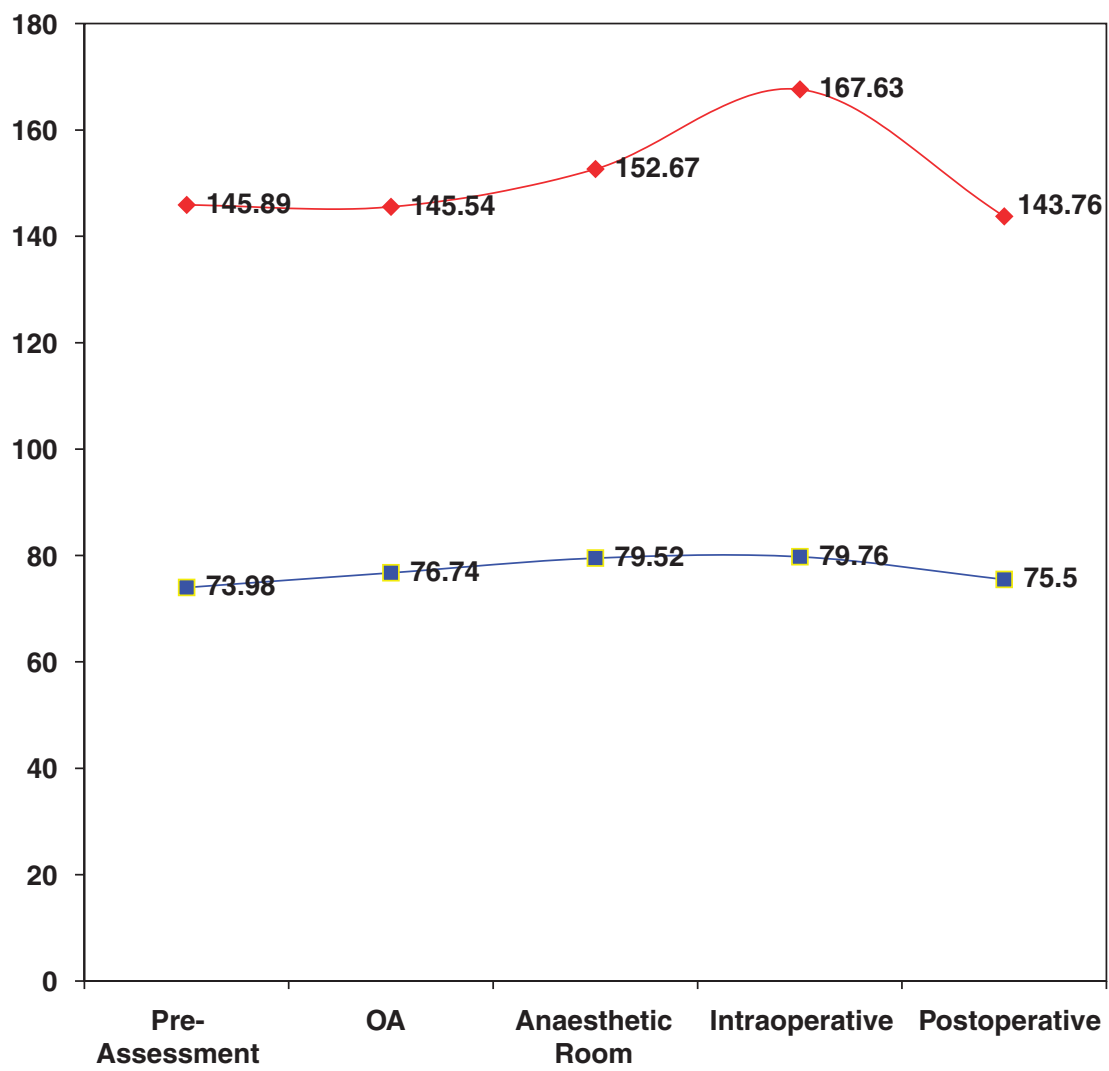

$\longrightarrow$ Systolic BP —-Diastolic BP

Figure 1 Change in mean systolic and diastolic blood pressures in five different settings.

Table 1 Descriptive profile of study subjects

\begin{tabular}{|c|c|c|}
\hline & Number (N) & Percentage (\%) \\
\hline Total & 46 & \\
\hline \multicolumn{3}{|l|}{ Gender } \\
\hline Male & 19 & 41.3 \\
\hline Female & 27 & 58.7 \\
\hline \multicolumn{3}{|l|}{ Age (years) } \\
\hline$\leqslant 65$ & 6 & 13.0 \\
\hline$>65$ & 40 & 87.0 \\
\hline \multicolumn{3}{|c|}{ Hypertensive } \\
\hline Yes & 27 & 58.7 \\
\hline \multicolumn{3}{|c|}{ Family history of hypertension } \\
\hline Yes & 6 & 13.0 \\
\hline \multicolumn{3}{|c|}{ Antihypertensive medication } \\
\hline Yes & 12 & 26.1 \\
\hline
\end{tabular}

Patients' demographics with gender ratio, age, history of hypertension, family history, and percentage on antihypertensives.

positions. The highest blood pressure readings were recorded intraoperatively and it is not known which phacoemulsification steps was done during the rise in
Table 2 Comparison of the mean systolic blood pressures between preassessment and anaesthetic room $v s$ intraoperatively

\begin{tabular}{|c|c|c|c|c|}
\hline & \multicolumn{4}{|c|}{ Change in systolic blood pressure $(\mathrm{mmHg})$} \\
\hline & Mean & $\begin{array}{c}\text { Difference } \\
\text { in mean }\end{array}$ & $95 \% C I$ & P-value \\
\hline Preassessment & 145.9 & 21.7 & $15.5-7.9$ & $<0.001$ \\
\hline Intraoperative & 167.6 & & & \\
\hline Anaesthetic room & 152.7 & 15.0 & $10.2-9.7$ & $<0.001$ \\
\hline Intraoperative & 167.6 & & & \\
\hline
\end{tabular}

CI, confidence interval

The rise in systolic blood pressure intraoperatively is statistically significant.

blood pressure. It would be good to include monitoring of the blood pressure during different stages of the procedure with the involvement of more patients in future studies

Variability in responses may be due to blood pressures measurements taken at different stages intraoperatively. They also reflect the range in response of blood pressures between individuals during cataract surgery. 
Table 3 Comparison of the mean diastolic blood pressures between preassessment and anaesthetic room vs intraoperatively

\begin{tabular}{lcccc}
\hline & \multicolumn{4}{c}{ Change in diastolic blood pressure $(\mathrm{mm} \mathrm{Hg})$} \\
\cline { 2 - 5 } & Mean & Difference in mean & $95 \%$ CI & P-value \\
\hline $\begin{array}{l}\text { Preassessment } \\
\text { Intraoperative }\end{array}$ & 74.0 & 5.8 & $0.30-1.3$ & 0.04 \\
Anaesthetic room & 79.8 & & & \\
Intraoperative & 79.8 & 0.3 & $10.2-9.7$ & 0.92 \\
& & & & \\
\hline
\end{tabular}

Abbreviation: CI, confidence interval.

It is moderately statistically significant between preassessment $v$ intraoperatively but not significant between anaesthetic room $v s$ intraoperatively.

Table 4 Outlining the different hypothesis test. Mean change in systolic blood pressure (mmHg) preassessment clinic vs intraoperatively

\begin{tabular}{|c|c|c|c|c|c|}
\hline & \multicolumn{5}{|c|}{ Mean change in systolic blood pressure $(\mathrm{mm} \mathrm{Hg})$ pre-assessment clinic vs intra-operatively } \\
\hline & Number $(\mathrm{N})$ & Mean change in $B P$ & Difference & $95 \% \mathrm{CI}$ & P-value \\
\hline \multicolumn{6}{|l|}{ Age (years) } \\
\hline$\leqslant 65$ & 6 & 13.5 & -9.48 & $-27.9-8.9$ & 0.30 \\
\hline$>65$ & 40 & 23.0 & & & \\
\hline \multicolumn{6}{|l|}{ Gender } \\
\hline Male & 19 & 15.0 & -11.5 & $-23.7-0.74$ & 0.07 \\
\hline Female & 27 & 26.5 & & & \\
\hline \multicolumn{6}{|c|}{ Hypertension } \\
\hline Yes & 19 & 21.2 & -1.34 & $-14.1-11.4$ & 0.83 \\
\hline No & 27 & 22.5 & & & \\
\hline \multicolumn{6}{|c|}{ Antihypertensives } \\
\hline$<2$ & 34 & 22.2 & 1.90 & $-12.4-16.5$ & 0.79 \\
\hline$\geqslant 2$ & 12 & 20.3 & & & \\
\hline \multicolumn{6}{|c|}{ Family history } \\
\hline Yes & 6 & 15.7 & -6.98 & -25.511 .5 & 0.45 \\
\hline No & 40 & 22.7 & & & \\
\hline
\end{tabular}

Abbreviations: CI, confidence interval, BP, blood pressure.

Note that for comparison between gender, there is a statistical significant rise in systolic blood pressure for females while the other risk factors are not significant.

Understanding the variation of blood pressures intraoperatively and identification of at-risk patients will help to make procedure safer (Figure 1; Tables 1-4).

\section{References}

1 Patel BC, Burns TA, Crandall A, Shomaker ST, Pace NL, van Eerd A et al. A comparison of topical and retrobulbar anesthesia for cataract surgery. Ophthalmology 1996; 103(8): 1196-1203.

2 Ling R, Cole M, James C, Kamalarajah S, Foot B, Shaw S. Suprachoroidal haemorrhage complicating cataract surgery in the UK: epidemiology, clinical features, management, and outcomes. Br J Ophthalmol 2004; 88(4): 478-480.

3 Suzuki R, Kuroki S, Fujiwara N, Umemoto S. The effects of phacoemulsification cataract surgery via local anesthesia on preoperative and postoperative blood pressure levels. Ophthalmology 1997; 104(2): 216-222.

4 Mamiya K, Manabe M, Aono J, Ueno H. Blood pressure control during eye surgery under local anaesthesia using pulse oximetry. Ophthalmologica 1998; 212(4): 236-238.

5 Fichman RA. Use of topical anesthesia alone in cataract surgery. J Cataract Refract Surg 1996; 22(5): 612-614.

6 Szmyd Jr L, Schwartz B. Association of systemic hypertension and diabetes mellitus with cataract extraction. A case-control study. Ophthalmology 1989; 96(8): 1248-1252. 
7 Kenawy NB, Jabir M. Phenylephrine $2.5 \%$ and $10 \%$ in phacoemulsification under topical anaesthesia: is there an effect on systemic blood pressure? Br J Ophthalmol 2003; 87(4): 505-506.

8 Malhotra R, Banerjee G, Brampton W, Price NC. Comparison of the cardiovascular effects of $2.5 \%$ phenylephrine and $10 \%$ phenylephrine during ophthalmic surgery. Eye 1998; 12(Part 6): 973-975.

9 Symons RC, Walland MJ, Kaufman DV. A comparative study of the efficacy of $2.5 \%$ phenylephrine and $10 \%$ phenylephrine in pre-operative mydriasis for routine cataract surgery. Eye 1997; 11(Part 6): 946-948. 